\title{
Clinical pharmacology of lorazepam in infants and children
}

\author{
Gian Maria Pacifici \\ Associate Professor of Pharmacology via Sant’ Andrea 32, 56127 Pisa, Italy.
}

Corresponding Author: Gian Maria Pacifici, Associate Professor of Pharmacology via Sant' Andrea 32, 56127 Pisa, Italy.

Received date: October 11, 2021: Accepted date: November 05, 2021: Published date: January 03,2022

Citation: Gian Maria Pacifici, (2022) Clinical pharmacology of lorazepam in infants and childrenJ. Clin Case Rep and Stu 3(1); DOI: 10.31579/26908808/094

Copyright: (C) 2022 Gian Maria Pacifici, This is an open access article distributed under the Creative Commons Attribution License, which permits unrestricted use, distribution, and reproduction in any medium, provided the original work is properly cited.

\begin{abstract}
Lorazepam is a benzodiazepine has antiepileptic activity; it may be administered intravenously, intramuscularly, orally, by intranasal or buccal application and following oral dosing it is well absorbed. In infants, the initial intravenous dose of lorazepam is $100 \mu \mathrm{g} / \mathrm{kg}$ and in children the initial oral and intravenous dose is 50 to $100 \mu \mathrm{g} / \mathrm{kg}$ and the dose varies according to the child age. Lorazepam has been found efficacy and safe in infants and children but it may induce adverseeffects. Lorazepam is a racemate and the $\mathrm{R}$ and $\mathrm{S}$ enantiomers are conjugated with glucuronic acid in human liver microsomes and the respective $\mathrm{Km}$ and Vmax values are $29 \pm 8.9$ and $36 \pm 10 \mu \mathrm{M}$ and $7.4 \pm 1.9$ and $10 \pm 3.8 \mathrm{pmol} / \mathrm{min} * \mathrm{mg}$. Lorazepam interacts with drugs and the interaction may affect the activity or metabolism of lorazepam. The pharmacokinetics of lorazepam have been studied in infants and children and in diseased children. In infants and children the elimination half-life is about 15 hours and it is about 24 hours and about 37 hours in children with severe malaria and convulsions following intravenous and intramuscular administration, respectively. The treatment and trials with lorazepam have been studied in infants and children. Lorazepam freely crosses the human placenta and poorly migrates into the breast-milk. The aim of this study is to review the published data on lorazepam dosing, efficacy and safety, adverse-effects, metabolism, interaction with drugs, pharmacokinetics, treatment and trials in infants and children and the lorazepam transfer across the human placenta and migration into the breast-milk.
\end{abstract}

Running title: Lorazepam in infants and children.

Key words: lorazepam; efficacy and safety; adverse-effects; metabolism; drug interaction; pharmacokinetics; treatment; trials; placenta; breast-milk; infants; children

\section{Introduction}

The success of the first benzodiazepine, chlordiazepoxide (Librium ${ }^{\circledR}$ ), in 1960 triggered the development of a number or related products including diazepam (licensed in 1963) and lorazepam (licensed a year later). They are widely, and liberality, used to treat anxiety before it came to be accepted that such use should always be limited to the lowest possible dose for the shortest possible time. Dependence can become a serious problem, even with careful prescribing. Lorazepam is well absorbed when taking by mouth, conjugated into an inactive glucuronide in the liver, and then excreted in the urine by glomerular filtration. The elimination halflife in the neonatal period is 30 to 50 hours (two to three times as long as in adults). The tissue levels of lorazepam exceed plasma levels and the distribution volume is about $1.3 \mathrm{~L} / \mathrm{kg}$. Most benzodiazepines are of limited value in long-term treatment of epilepsy but have an important role in the management of prolonged seizures. Diazepam was the first to be widely used. Clonazepam, lorazepam, and midazolam have all been used. There is, however, continuing concern that, while the benzodiazepine may well abolish the physical signs of the seizure, electrical seizure activity may still sometimes persist. Rapid intravenous administration in the infant can sometimes precipitate hypotension, respiratory depression, and abnormal seizure-like movements, especially in response to the first dose given. Withdrawal symptoms are also very common after sustained use even if the dose given is lowered slowly. Lorazepam readily crosses the placenta, but there is no evidence of teratogenicity. Maternal use, particularly if high doses are used, in the third trimester or during labour may cause hypothermia, lethargy, poor feeding, or neonatal withdrawal. Lorazepam is excreted into breast-milk in small amounts (about 5 to $10 \%$ of the maternal dose). Breastfeeding may further sedate an already affected infant in the immediate postnatal period but sustained use during lactation does not seem to cause noticeable drowsiness [1]. Lorazepam is used for the acute management of infants with seizures refractory to conventional therapy. Lorazepam is incompatible with fat emulsion, aztreonam, caffeine citrate, and imipenem/cilastatin [2]. 


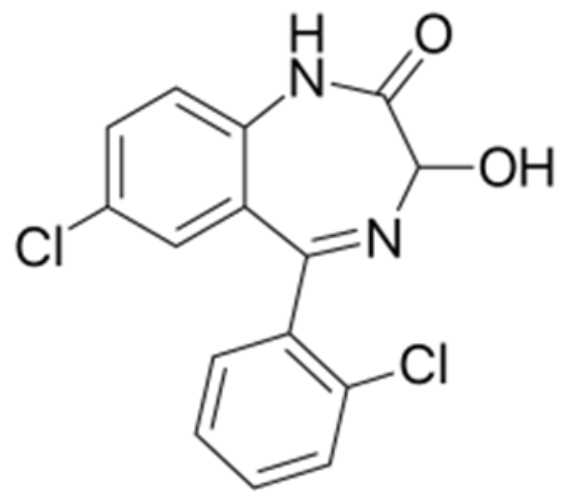

Lorazepam molecular structure (molecular weight $=321.2$ grams $/$ mole)

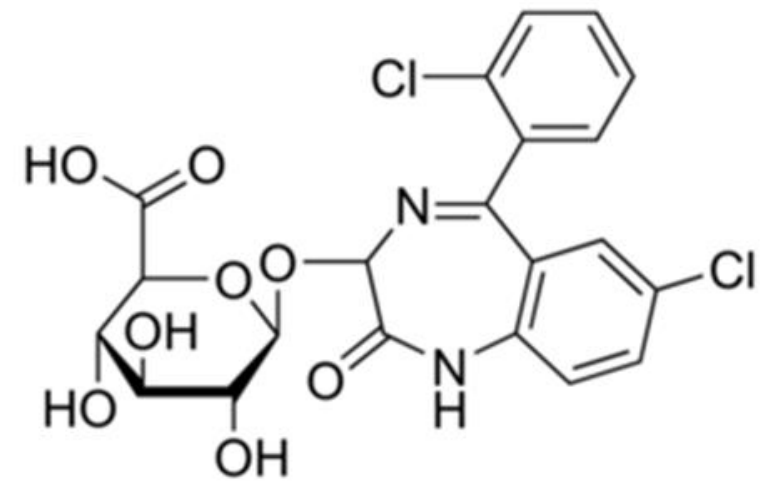

Lorazepam glucuronide molecular structure (molecular weight $=497.282 \mathrm{gams} / \mathrm{mole}$ )

\section{Literature search}

The literature search was performed electronically using PubMed database as search engine and the following key words were used: "lorazepam dosing infants, children", "lorazepam efficacy safety infants, children", "lorazepam adverse-effects infants, children", "lorazepam metabolism", "lorazepam drug interactions", "lorazepam pharmacokinetics infants, children", "lorazepam treatment infants, children", "lorazepam trials infants, children", "lorazepam placental transfer", and "lorazepam breast-milk". In addition, the books: Neonatal Formulary [1], NEOFAX ${ }^{\circledR}$ by Young and Mangum [2], and The British National Formulary for Children [3] are consulted.

\section{Results}

\section{Administration schedules of lorazepam to infants and children}

\section{Administration to infants [1]}

Dose: A single $100 \mu \mathrm{g} / \mathrm{kg}$ dose usually stop all visible seizures activity within $10 \mathrm{~min}$. Whist this can be repeated after $10 \mathrm{~min}$ the long elimination half-life in early infancy increases the risk of sedation and respiratory depression.

\section{Route of administration}

Lorazepam is normally given by slow intravenous infusion over 3 to 5 $\mathrm{min}$. The buccal and intranasal routes, whilst not well studied, do not seem to be almost equally effective (at least in infants more than a few weeks old). Lorazepam can also be given by mouth, but intramuscular administration is painful and best avoided. Sustained infusion can cause a progressive accumulation of the potentially toxic excipient propylene glycol.

Administration to children [3] Oral premedication.
Children aged 1 month to 11 years. Give: 50 to $100 \mu \mathrm{g} / \mathrm{kg}$ (maximum per dose $=4 \mathrm{mg}$ ). The dose should be given at least 1 hour before procedure, and the same dose may be given the night before procedure in addition to, or to replace, dose before the procedure.

Children aged 12 to 17 years. Give: 1 to $4 \mathrm{mg}$, to be given at least 1 hour before the procedure, the same dose may be given at night before the procedure in addition to, or to replace, dose before the procedure. Intravenous administration for the treatment of premedication

Children. Give: 50 to $100 \mu \mathrm{g} / \mathrm{kg}$ (maximum per dose $=4 \mathrm{mg}$ ), to be administered 30 to $45 \mathrm{~min}$ before the procedure .Intravenous administration for the treatment of the status epilepticus, febrile convulsions, or convulsions caused by poisoning

Children aged 1 month to 11 years. Give: $100 \mu \mathrm{g} / \mathrm{kg}$ (maximum per dose $=4 \mathrm{mg}$ ) for $1 \mathrm{dose}$, and then $100 \mu \mathrm{g} / \mathrm{kg}$ after $10 \mathrm{~min}$ (maximum per dose $=4 \mathrm{mg}$ ) if required for 1 dose, to be administered into a large vein.

Children aged 12 to 17 years. Give: $4 \mathrm{mg}$ for 1 dose, and then $4 \mathrm{mg}$ after $10 \mathrm{~min}$ if required for 1 dose, to be administered into a large dose.

\section{Efficacy and safety of lorazepam in children}

Lorazepam has been found efficacy and safe in children and the most common adverse-effects are somnolence $(7.7 \%)$ and insomnia $(7.7 \%)$, and almost all adverse-effects are mild or moderate in severity [4]. Intranasal lorazepam is effective, safe, and provides a less invasive alternative to intramuscular paraldehyde in children with protracted convulsions [5]. Intravenous lorazepam is the first-line therapy in preference to intravenous diazepam in children with convulsive status epilepticus [6]. Lorazepam is superior to intravenous or non-intravenous diazepam, and intravenous lorazepam is at least as effective as nonintravenous midazolam in treating paediatric status epilepticus [7]. 
Lorazepam induces the most sedation immediately after surgery compared to diazepam and trimeprazine [8].

Common or very common adverse-effects caused by lorazepam in infants and children [3]

Apnoea, asthenia, coma, disinhibition, extrapyramidal symptoms, hypothermia, memory loss, speech slurred, and suicide attempt.

Uncommon adverse-effects caused by lorazepam in infants and children [3]

Allergic dermatitis, constipation, and sexual dysfunction.

Rare or very rare adverse-effects caused by lorazepam in infants and children [3]

Agranulocytosis, hyponatraemia, pancytopenia, and thrombocytopenia.

\section{Metabolism of Iorazepam}

The kinetics of the separate $\mathrm{R}$ and $\mathrm{S}$ enantiomers of lorazepam were characterised in human liver microsomes and by a panel of recombinant human UDP-glucuronosyltransferase enzymes. Respective mean $\mathrm{Km}$ and Vmax values for R- and S-lorazepam glucuronidation by human liver microsomes are $29 \pm 8.9$ and $36 \pm 10 \mu \mathrm{M}$, and $7.4 \pm 1.9$ and $10 \pm 3.8$ $\mathrm{pmol} / \mathrm{min} * \mathrm{mg}$. Microsomal intrinsic clearances were not significantly different, suggesting the in-vivo clearances of R- and S-lorazepam are likely to be similar. Both R- and S-lorazepam are glucuronidated by UGT2B4, UGT2B7, and UGT2B15, whereas R-lorazepam is additionally metabolized by the extrahepatic enzymes UGT1A7 and UGT1A10. Based on in-vitro clearances and consideration of available in-vivo and in-vitro data, UGT2B15 is likely to play an important role in the glucuronidation of R- and S-lorazepam [9]. The principal metabolite of lorazepam is lorazepam glucuronide. Blood concentrations of unconjugated lorazepam peak 1 to 4 hours following dosing. Significant concentrations persist for 24 hours and slowly decrease over the next 24 hours. About $95 \%$ of a dose of lorazepam is recovered in the urine and faeces over a period of 5 days;
$74.5 \%$ is excreted in the urine as lorazepam glucuronide and $13.5 \%$ as minor metabolites [10]. Absorption of oral lorazepam is nearly complete and lorazepam glucuronide is the major metabolite and dihydrodiol derivative is another metabolite [11]. Lorazepam and lorazepam glucuronide are the only detected compounds up to 12 hours following lorazepam administration and the amount of lorazepam glucuronide exceeded that of lorazepam in blood and urine [12].

\section{Interaction of lorazepam with drugs}

Metoprolol causes a small increase in critical flicker fusion threshold with lorazepam [13]. The effect of lorazepam in doses of $2 \mathrm{mg}$ and $4 \mathrm{mg}$ combined with morphine $5 \mathrm{mg}$ produces sedation, relief of anxiety, lack of recall, and patient acceptance [14]. Lorazepam combined with mirogabalin increases somnolence [15]. The UGT2B7 genotype affects lorazepam-valproate pharmacodynamic interaction especially in subjects who have homovariant genotypes of UGT2B7 and UGT2B15 [16]. Pretreatment with $1 \mathrm{mg} / \mathrm{kg}$ of 4,5,6,7-tetrahydroisoxazolo [5,4-c]pyrindin-3ol attenuates the rate-increasing effects of lorazepam on non-suppressed responding [17]. Moxonidine, when co-administered with lorazepam, produces interactions with three tasks requiring high levels of attention reduces vigilance performance, memory tasks, and visual tracking [18]. Caffeine citrate $(500 \mathrm{mg}$ ) counteracts the lorazepam effect of reducing anxiety and making the subject feel more relaxed [19]. Lorazepam treatment should not be combined with even small quantities of alcohol because of the risk of both psychomotor impairment and possible anxiogenic effects [20]. Cimetidine increased the absorption-rate of diazepam and lorazepam [21].

\section{Pharmacokinetics of lorazepam in infants and children}

Gonzalez et al. [22] studied the pharmacokinetics of lorazepam in 145 infants and children and lorazepam was administrated intravenously. Table 1 summarized the lorazepam dose and the demographic characteristics of subjects included in the study.

\begin{tabular}{|c|c|c|c|c|}
\hline Variable & $\begin{array}{c}3 \text { months to 3 years } \\
(\mathrm{N}=54)\end{array}$ & 3 to 13 years $(\mathrm{N}=69)$ & $\geq 13$ years $(\mathrm{N}=22)$ & Total $(\mathrm{N}=145)$ \\
\hline Dose $(\mathrm{mg} / \mathrm{kg})$ & $0.10(0.04-0.18)$ & $0.09(0.02-0.12)$ & $0.04(0.02-0.10)$ & $0.10(0.02-0.18)$ \\
\hline Age $($ years $)$ & $1.3(0.3-2.9)$ & $6.5(3.0-12.0)$ & $15.9(13.8-17.8)$ & $5.4(0.3-17.8)$ \\
\hline Body-weight $(\mathrm{kg})$ & $10(2-20)$ & $23(10-83)$ & $68(36-105)$ & $18(2-105)$ \\
\hline
\end{tabular}

Table 1. Clinical data for population pharmacokinetic model development. Figures are the median and (range), by Gonzalez et al. [22].

\begin{tabular}{|c|c|c|c|c|c|}
\hline & \multicolumn{2}{|c|}{ Final model } & \multicolumn{3}{c|}{ Bootstrap (N = 1,000) } \\
\hline Parameter & Point estimate & \%RSE & $2.5 \%$ & Median & $97.5 \%$ \\
\hline CDV (L/kg) & 0.879 & 11.2 & 0.607 & 0.786 & 0.969 \\
\hline TBC (L/h/kg $\left./ \mathrm{kg}^{0.75}\right)$ & 0.115 & 5.5 & 0.108 & 0.119 & 0.131 \\
\hline $\mathrm{PDV}(\mathrm{L} / \mathrm{kg})$ & 0.542 & 32.7 & 0.452 & 0.737 & 1.250 \\
\hline $\mathrm{Q}\left(\mathrm{L} / \mathrm{h} / \mathrm{kg}^{0.75}\right)$ & 1.450 & 50.8 & 1.100 & 2.520 & 4.981 \\
\hline Between subject variability (\%Coefficient of variation) \\
\hline nCDV & $75 \%$ & $37 \%$ & $50 \%$ & $60 \%$ & $75 \%$ \\
\hline nTBC & $40 \%$ & $18 \%$ & $75 \%$ & $81 \%$ & $86 \%$ \\
\hline nPDV & $57 \%$ & $91 \%$ & $17 \%$ & $48 \%$ & $85 \%$ \\
\hline
\end{tabular}

$\mathrm{CDV}=$ central distribution volume. $\mathrm{TBC}=$ total body clearance. $\mathrm{PDV}=$ peripheral distribution volume. $\mathrm{Q}=$ intercompartmental clearance. $\% \mathrm{RSE}=$ \%relative standard error of estimate.

\section{Table 2. Pharmacokinetic parameters for the final population model, by Gonzalez et al. [22].}

This table shows that the central median distribution volume is similar to the peripheral distribution volume and there is a remarkable interindividual variability in pharmacokinetic parameters. This variability is accounted by the wide variability of the demographic characteristics of the subjects included in the study.

Chamberlain et al. [23] investigated the pharmacokinetics of lorazepam in 168 infants and children, lorazepam was administered intravenously, 
the dose was computed according the subject body-weight, and the mean dose is $5.3 \mathrm{mg}(0.16 \mathrm{mg} / \mathrm{kg})$. Fifty-two subjects are aged 3 months to $<3$ years, 72 subjects are aged 3 to $<13$ years, and 44 subjects are aged 13 to 18 years.

\begin{tabular}{|c|c|c|c|c|c|c|}
\hline & Peak conc. $(\mathrm{ng} / \mathrm{ml})$ & $\begin{array}{c}\mathrm{AUC}-\infty \\
(\mathrm{ng} / \mathrm{ml} / \mathrm{h})\end{array}$ & $\begin{array}{c}\mathrm{TBC} \\
(\mathrm{ml} / \mathrm{min} / \mathrm{kg})\end{array}$ & $\begin{array}{c}\mathrm{TBC} \\
\left(\mathrm{ml} / \mathrm{min} / \mathrm{m}^{2}\right)\end{array}$ & DV (L/h) & Elimination half-life (h) \\
\hline $\mathrm{N}$ & 15 & 15 & 15 & 15 & 15 & 15 \\
\hline Range & $29.3-210$ & $253-3,202$ & $3.33-131$ & $5.5-67.5$ & $0.33-4.05$ & $9.5-47.0$ \\
\hline Mean+SD & $56.1 \pm 44.9$ & $822 \pm 706$ & $49.3 \pm 30.8$ & $31.9 \pm 14.0$ & $1.9 \pm 0.84$ & $20.5 \pm 10.2$ \\
\hline Median & 42.2 & 601 & 41.5 & 32.4 & 1.94 & 18.1 \\
\hline
\end{tabular}

$\mathrm{TBC}=$ total body clearance. $\mathrm{DV}=$ distribution volume.This table shows that the distribution volume of lorazepam is larger than the water volume lorazepam is slowly eliminated from the body, and there is a remarkable interindividual variability in the pharmacokinetic parameters. This variability is accounted by the wide variation of the subject demographic characteristics.

Table 3. Non-compartmental pharmacokinetic parameters of lorazepam which are obtained in 90 infants and children, by Chamberlain et al. [23].

\begin{tabular}{|c|c|c|c|c|c|c|}
\hline & Free fraction & TBC $(\mathrm{ml} / \mathrm{min} / \mathrm{kg})$ & TBC $\left(\mathrm{ml} / \mathrm{min} / \mathrm{m}^{2}\right)$ & DVss $(\mathrm{L} / \mathrm{kg})$ & $\beta\left(\mathrm{h}^{-1}\right)$ & Elimination half-life $(\mathrm{h})$ \\
\hline \multicolumn{7}{|c|}{ All subjects } \\
\hline $\mathrm{N}$ & 61 & 63 & 63 & 63 & 63 & 63 \\
\hline Range & $0.07-0.48$ & $0.30-7.75$ & $6.50-147$ & $0.19-3.40$ & $0.017-0.118$ & $5.9-42.0$ \\
\hline Mean \pm SD & $0.10 \pm 0.05$ & $1.2 \pm 0.93$ & $3.33 \pm 19.3$ & $1.48 \pm 0.54$ & $0.48 \pm 0.020$ & $16.8 \pm 7.1$ \\
\hline Median & 0.09 & 1.08 & 29.00 & 1.37 & 0.046 & 15.1 \\
\hline \multicolumn{7}{|c|}{ Subjects aged 3 months to 3 years } \\
\hline $\mathrm{N}$ & 17 & 18 & 18 & 18 & 18 & 18 \\
\hline Range & $0.07-0.48$ & $0.63-7.75$ & $12.83-147$ & $0.67-3.40$ & $0.024-0.118$ & $5.9-28.4$ \\
\hline Mean+SD & $0.11 \pm 0.10$ & $1.57 \pm 1.62$ & $32.8 \pm 30.2$ & $1.62 \pm 0.59$ & $0.053 \pm 0.027$ & $15.8 \pm 6.5$ \\
\hline \multicolumn{7}{|c|}{ Subjects aged 3 to 13 years } \\
\hline N & 28 & 29 & 29 & 29 & 29 & 29 \\
\hline Range & $0.07-0.17$ & $0.30-1.82$ & $6.50-39.17$ & $0.49-3.00$ & $0.017-0.092$ & $7.5-40.6$ \\
\hline Mean+SD & $0.10 \pm 0.02$ & $1.12 \pm 0.40$ & $31.83 \pm 13.83$ & $1.50 \pm 0.61$ & $0.048 \pm 0.017$ & $16.9 \pm 7.4$ \\
\hline \multicolumn{7}{|c|}{ Subjects aged 13 to 18 years } \\
\hline N & 16 & 16 & 16 & 16 & 16 & 16 \\
\hline Range & $0.07-0.15$ & $0.43-1.58$ & $16.33-60.00$ & $1.00-1.54$ & $0.017-0.84$ & $8.2-42.0$ \\
\hline Mean+SD & $0.09 \pm 0.02$ & $0.95 \pm 0.32$ & $36.67 \pm 12.00$ & $1.27 \pm 0.17$ & $0.044 \pm 0.016$ & $17.8 \pm 7.7$ \\
\hline
\end{tabular}

$\mathrm{TBC}=$ total body clearance. $\mathrm{DVss}=$ distribution volume at the steady-state. $\beta=$ terminal slope of the log concentration versus time profile.

Table 4. Bayesian pharmacokinetic parameters of lorazepam which are obtained in 168 infants and children, by Chamberlain et al. [23].

This table shows that lorazepam distribution volume is larger than the water volume, lorazepam is slowly eliminated, and there is a remarkable interindividual variability in the pharmacokinetic parameters. This interindividual variability is due to the wide variation of the demographic characteristics of the subjects included in the study.

\section{Pharmacokinetics of Iorazepam in diseased children}

Muchohi et al. [24] studied the pharmacokinetics of lorazepam in 26 children with severe malaria and convulsions. A single dose of 0.1 $\mathrm{mg} / \mathrm{kg}$ of lorazepam was administered intravenously to 15 children and intramuscularly to 11 children.

\begin{tabular}{|c|c|c|c|}
\hline & Intravenous lorazepam & Intramuscular lorazepam & 95\% CI for the difference between the means or median \\
\hline Number of children & 15 & 11 & --- \\
\hline Sex (male/female) & $15(6: 9)$ & $11(6: 5)$ & $-16,16.0$ \\
\hline Age (months) & $32.0(8-91)$ & $28.0(6-78)$ & $-3.07,2.44$ \\
\hline Body-weight $(\mathrm{kg})$ & $10.8(9.2-12.4)$ & $11.1(8.5-13.7)$ & ---- \\
\hline
\end{tabular}

Table 5. Demographic characteristics of children included in the study. Figures are the mean and [95\% confidence interval (CI)], by Muchohi et al. [24].

\begin{tabular}{|c|c|c|c|c|c|}
\hline Parameter & $\mathrm{N}$ & $\begin{array}{c}\text { Intravenous } \\
\text { lorazepam }\end{array}$ & $\mathrm{N}$ & $\begin{array}{c}\text { Intramuscular } \\
\text { lorazepam }\end{array}$ & $\begin{array}{c}\text { 95\% CI for the difference between the } \\
\text { means or medians }\end{array}$ \\
\hline Peak conc. (ng/ml) & 11 & $65.1(47.5-86.0)$ & $\begin{array}{c}1 \\
0\end{array}$ & $45.3(29.6-66.3)$ & $-43.5,5.0$ \\
\hline Time to achieve peak conc. (h) & 11 & $0.50(0.17-0.67)$ & $\begin{array}{c}1 \\
0\end{array}$ & $0.42(0.17-1.00)$ & $-0.33,0.17$ \\
\hline Elimination half-life $(\mathrm{h})$ & 9 & $23.7(9.8-37.6)$ & 5 & $36.9(-1.5-75.5)$ & $-41.3,14.9$ \\
\hline $\mathrm{AUC}_{0-\infty}(\mathrm{ng} / \mathrm{ml} / \mathrm{h})$ & 9 & $2,062(601-3,771)$ & 5 & $1,844(297-3,390)$ & $-1,268,1,883$ \\
\hline
\end{tabular}




\begin{tabular}{|c|c|c|c|c|c|}
\hline $\mathrm{Ka}\left(\mathrm{h}^{-1}\right)$ & 9 & --- & 6 & $9.8(0.033-22.8)$ & --- \\
\hline Absorption half-life (h) & 9 & --- & 6 & $0.035(0.01-0.07)$ & --- \\
\hline Total body clearance (L/h) & 9 & $0.64(0.36-0.92)$ & 6 & --- & -- \\
\hline $\begin{array}{c}\text { Central distribution volume (L/kg) } \\
\begin{array}{c}\text { Distribution volume at steady-state } \\
(\mathrm{L} / \mathrm{kg})\end{array}\end{array}$ & 9 & $1.67(1.25-2.10)$ & 6 & --- & -- \\
\hline Bioavailability (F) & 9 & $100 \%$ & 6 & $89.4 \%$ & - \\
\hline
\end{tabular}

Table 6. Pharmacokinetic parameters of lorazepam which are obtained following administration of a single dose of $0.1 \mathrm{mg} / \mathrm{kg}$ either intravenously or intramuscularly to children with severe malaria and convulsions. Figures are the mean and [95\% confidence interval (CI)], by Muchohi et al. [24].

This table shows that the peak concentration, the time to achieve the peak concentration, the elimination half-life, and AUC are similar according to the two routes of lorazepam administration. Following intramuscular administration, lorazepam is rapidly and almost completely absorbed. The comparison of the pharmacokinetic parameters obtained in children with those obtained in infants and children (see tables 3 and 4) is difficult because of the different demographic characteristics of the subjects included in the studies and the diseases suffered from children.

\section{Treatment with lorazepam in infants and children}

Lorazepam is an effective agent in the treatment of neonatal seizures refractory to phenobarbital [25]. Treatment with lorazepam causes immediate cessation of seizure activity in all infants within $5 \mathrm{~min}$ [26]. Lorazepam is increasingly used in the treatment of refractory neonatal seizures [27]. In children, intravenous lorazepam and intravenous diazepam are efficacious for stopping seizures lasting at least 5 min [28]. Intravenous lorazepam is associated with a 3.7 times greater likelihood of seizure termination than is treatment with rectal diazepam [29]. The childhood seizure is successfully controlled $15 \mathrm{~min}$ after intravenous diazepam and after $5 \mathrm{~min}$ with intravenous lorazepam [30]. Lorazepam is a safe and effective agent to treat acute convulsions in children with status epilepticus [31]. Sublingual lorazepam is an easy and effective agent for treating serial childhood seizures at home [32]. Convulsions are controlled in $76 \%$ children treated with a single rectal dose of lorazepam and in $51 \%$ children treated with a single rectal dose of diazepam [33].

\section{Trials with lorazepam in children}

Lorazepam is the safer benzodiazepine for oral maintenance treatment of methamphetamine-induced convulsions [34]. Intravenous lorazepam is at least as effective as intravenous diazepam in treating acute tonic-clonic convulsions in children and lorazepam is associated with fewer adverseeffects [35]. Intravenous lorazepam is at least as effective as intravenous diazepam in controlling childhood seizures and is associated with fewer adverse-effects in the treatment of acute tonic-clonic convulsions [36]. Intravenous lorazepam is superior to intravenous diazepam in the treatment of paediatric status epilepticus [37]. Intranasal lorazepam has more favourable pharmacokinetics than buccal lorazepam when considering the need for the rapid blood concentrations required for seizure termination in children [38].

\section{Transfer of lorazepam across the human placenta}

Placental transfer of lorazepam evaluated as the ratio of vein umbilical to maternal vein plasma concentrations is 0.73 (range, 0.52-0.94) [39]. Lorazepam was administered intravenously at a dose of $2.5 \mathrm{mg}$ to pregnant mothers before surgical induction of labour or at the beginning of the second stage of labour. Lorazepam serum concentrations in newborns are similar to those in the maternal serum and rarely exceed the maternal concentrations [40].

\section{Migration of lorazepam into the breast-milk}

Lorazepam exposure through breast-milk is small, thus the maternal drug treatment and breastfeeding are compatible [41]. Following therapeutic dosing of lorazepam, the concentration of lorazepam in the breast-milk ranges from 55.3 to $123 \mathrm{ng} / \mathrm{ml}$ [42]. Measurable concentrations of lorazepam is demonstrated in all but 1 of the 35 breast-milk samples and the mean lorazepam concentration is $2.6 \pm 1.5 \mathrm{ng} / \mathrm{ml}$ (range, 0 to 7.0 ) [43]. Lactating women were treated with oral lorazepam twice-daily at a dose of $2.5 \mathrm{mg}$ for the first 5 days postpartum and the concentrations of free and glucuronide lorazepam are 12 and $35 \mathrm{ng} / \mathrm{ml}$, respectively [44].

\section{Discussion}

Lorazepam is a benzodiazepine has antiepileptic activity and it is used in acute management of infants, and children with seizures refractory to conventional therapy. Lorazepam may be administered intravenously, intramuscularly, orally, or by intranasal or buccal application and following oral administration lorazepam is rapidly and almost completely absorbed. The tissue level of lorazepam exceeds the plasma level and lorazepam distribution volume is about $1.3 \mathrm{~L} / \mathrm{kg}$. The initial intravenous dose of lorazepam is $100 \mu \mathrm{g} / \mathrm{kg}$ in infants [1]. In children, the initial oral or intravenous dose is 50 to $100 \mu \mathrm{g} / \mathrm{kg}$ and the dose varies according to the child age [3]. Lorazepam has been found efficacy and safe in infants and children [4-8]. Lorazepam has been found efficacy and safe in children but it may induce somnolence and insomnia and the adverseeffects are mild [4], intranasal lorazepam is efficacy and safe and it is a less invasive alternative to intramuscular paraldehyde in children with convulsions [5]. Intravenous lorazepam is the first-line therapy in preference to intravenous diazepam in treating children with convulsive status epilepticus [6], intravenous lorazepam is superior to intravenous or non-intravenous diazepam and intravenous lorazepam is effective as nonintravenous midazolam in treating paediatric status epilepticus [7], lorazepam induces the most sedation immediately after surgery compared to diazepam and trimeprazine [8], and lorazepam may induce adverseeffects [3]. The metabolism of lorazepam has been studied in man [9-12]. Lorazepam is conjugated with glucuronic acid; lorazepam is a racemate and the respective mean $\mathrm{Km}$ and $\mathrm{Vmax}$ values of $\mathrm{R}$ and $\mathrm{S}$ enantiomers of lorazepam are $29 \pm 8.9$ and $36 \pm 10 \mu \mathrm{M}$ and $7.4 \pm 1.9$ and $10 \pm 3.9$ $\mathrm{pmol} / \mathrm{min} * \mathrm{mg}$ in human liver microsomes. Both R- and S-lorazepam are glucuronidated by UGT2B4, UGT2B7, and UGT2B15, whereas Rlorazepam is additionally metabolized by extrahepatic enzymes UGT1A7 and UGT1A10 [9]. Blood concentrations of unconjugated lorazepam peak 1 to 4 hours following dosing, lorazepam slowly decreases from blood and $74.5 \%$ and $13.5 \%$ of the dose are excreted in the urine as lorazepam glucuronide and as minor metabolites [10]. Absorption of oral lorazepam is nearly complete, lorazepam glucuronide is the major metabolite of lorazepam, lorazepam glucuronide concentration exceeds that of lorazepam in blood and urine, and both lorazepam and lorazepam glucuronide are eliminated in the urine $[11,12]$. Lorazepam interacts with drugs [13-21]. Metoprolol causes a small increase in critical flicker fusion threshold with lorazepam [13], lorazepam combined with morphine produces sedation, relief of anxiety, lack of recall, and patient acceptance [14], and lorazepam co-administered with mirogabalin increases somnolence [15]. The UGT2B7 genotype affects lorazepam-valproate pharmacodynamic interaction in subjects who have homovariant genotypes of UGT2B7 and UGT2B15 [16]. Pre-treatment with $1 \mathrm{mg} / \mathrm{kg}$ 
4,5,6,7-tetrahydroisoxazolo[5,4-c]pyrindin-3-ol attenuates the rateincreasing effects of lorazepam on non-suppressed responding [17]. The co-administration of moxonidine with lorazepam produces interactions with three tasks requiring high levels of attention, memory tasks, and visual tracking [18]. Caffeine citrate counteracts the lorazepam effect reducing anxiety and making the subjects feel more relaxed [19]. Lorazepam treatment should not be combined with alcohol because of the risk of both psychomotor impairment and possible anxiogenic effects [20], and cimetidine increases the absorption-rate of diazepam and lorazepam [21]. The pharmacokinetics of lorazepam have been studied in infants and children [22, 23] and in children with severe malaria and convulsions [24]. In infants and children, the median central and peripheral distribution volumes are 0.786 and $0.737 \mathrm{~L} / \mathrm{kg}$, respectively, indicating than the lorazepam concentrates in blood and in tissues in similar amounts [22] and the man elimination half-life ranges from 15.1 to 17.8 hours [23]. Lorazepam was administered intravenously or intramuscularly to children with severe malaria and convulsions and following intramuscularly administration lorazepam is rapidly absorbed and the mean absorption half-life of lorazepam is 0.035 hours. The mean elimination half-life is 23.7 hours following intravenous dosing and 36.9 hours following intramuscular dosing [24] suggesting that lorazepam is slowly eliminated following intramuscular administration because lorazepam slowly leaves from the muscle depot. The treatment with lorazepam in infants and children has been extensively studied [25-33]. Lorazepam is an effective agent in the treatment of neonatal seizures refractory to phenobarbital [25], lorazepam causes immediate cessation of seizures in infants within $5 \mathrm{~min} \mathrm{[26],} \mathrm{and} \mathrm{lorazepam} \mathrm{is} \mathrm{increasingly}$ used in the treatment of refractory neonatal seizures [27]. In children, intravenous lorazepam and intravenous diazepam stop seizures lasting at least $5 \mathrm{~min}$ [28], intravenous lorazepam has a greater likelihood of seizure termination than rectal diazepam [29] and intravenous lorazepam controls childhood seizures more rapidly than intravenous diazepam [30]. Lorazepam is an effective and safe agent to treat the status epilepticus in children [31], sublingual lorazepam easily and effectively controls serial seizures in children [32], and the convulsions are controlled in $76 \%$ of children treated with single rectal lorazepam and in $51 \%$ children treated with single rectal diazepam [33]. The trials with lorazepam have studied in children [34-38]. Lorazepam is the safer benzodiazepine for oral treatment of methamphetamine-induced convulsions [34]. Intravenous lorazepam and intravenous diazepam are similarly effective agents in treating children with acute tonic-clonic convulsions but lorazepam is associated with fewer adverse-effects [35], intravenous lorazepam is as effective as intravenous diazepam in controlling childhood seizures but lorazepam is associated with fever adverse-effects in the treatment of acute tonic-clonic convulsions [36], and intravenous lorazepam is superior to intravenous diazepam in the treatment of paediatric status epilepticus [37]. Intranasal lorazepam has more favourable pharmacokinetics than buccal lorazepam in termination seizures in children [38]. Lorazepam freely crosses the human placenta [39, 40], and lorazepam poorly migrates into the breast-milk [41-44].

In conclusion, lorazepam is a benzodiazepine and is the most active benzodiazepine in treating refractory convulsions resistant to conventional therapy in infants and children. Lorazepam may be administered intravenously, intramuscularly, orally or by intranasal and buccal application and following oral dosing it is rapidly absorbed. In infants, the initial intravenous dose is $100 \mu \mathrm{g} / \mathrm{kg}$ and the initial oral or intravenous dose is 50 to $100 \mu \mathrm{g} / \mathrm{kg}$ in children. Lorazepam has been found efficacy and safe in infants and children but it may induce adverseeffects. Lorazepam is glucuronidated by UGT2B4, UGT17A, and UGT1A10 and lorazepam interacts with drugs and the interaction with drugs affects lorazepam effects and metabolism. The pharmacokinetics of lorazepam have been studied in infants and children and in children with severe malaria and convulsions. The elimination half-life of lorazepam ranges from 15.1 to 17.8 hours in infants and children. In these diseased children, the mean elimination half-life is 23.7 hours following intravenous administration and 36.9 hours after intramuscular administration. The treatment and trials with lorazepam have been extensively studied and lorazepam freely crosses the placenta and poorly migrates into the breast-milk. The aim of this study is to review the clinical pharmacology of lorazepam in infants and children.

\section{Conflict of interests}

The authors declare no conflicts of financial interest in any product or service mentioned in the manuscript, including grants, equipment, medications, employments, gifts, and honoraria.

This article is a review and drugs have not been administered to men or animals.

\section{Acknowledgments}

The author thanks Dr. Patrizia Ciucci and Dr. Francesco Varricchio, of the Medical Library of the University of Pisa, for retrieving the scientific literature.

\section{References}

1. Neonatal Formulary (2020). "Lorazepam” Oxford University Press. $8^{\text {th }}$ Edition, Great Clarendon Street, Oxford, OX2, 6DP, UK, pp: 466-468.

2. Young TE, Mangum B. NEOFAX ${ }^{\circledR}$ (2010). "Lorazepam" Thomas Reuters Clinical Editorial Staff, 23rd Edition, Montvale, USA, pp: 216-217.

3. The British national formulary for children. "Lorazepam". (2019-2020). Macmillan, 78th Edition, Hampshire International Business Park, Hampshire, Lime Three Way, Basingstoke, Hampshire, UK, pp: 228-229.

4. Ohtsuka Y, Nakasato N, Nakazuru Y, Terada M. (2019) Efficacy and Safety of Lorazepam Intravenously Administered in Subjects with Status Epilepticus or Repetitive Seizures. Brain Nerve.; 71(8): 901-910.

5. Ahmad S, Ellis JC, Kamwendo H, Molyneux E. (2006) Efficacy and safety of intranasal lorazepam versus intramuscular paraldehyde for protracted convulsions in children: an open randomised trial. Lancet.; 367(9522): 1591-1597.

6. Cock HR, Schapira AHV.(2002) A comparison of lorazepam and diazepam as initial therapy in convulsive status epilepticus. QJM; 95(4): 225-231.

7. Zhao Z-Y, Wang H-Y, Wen B, Zhi-Bo Yang WB, Feng K, et al. (2016) A Comparison of Midazolam, Lorazepam, and Diazepam for the Treatment of Status Epilepticus in Children: A Network Meta-analysis. J Child Neurol.; 31(9): 1093-1107.

8. Lorazepam in children. Burtles R, Astley B. (1983) A doubleblind trial comparing lorazepam, diazepam, trimeprazine and placebo. Br J Anaesth.; 55(4): 275- 279.

9. Uchaipichat V, Suthisisang C, Miners JO. (2013) The glucuronidation of $\mathrm{R}$ - and S-lorazepam: human liver microsomal kinetics, UDP-glucuronosyltransferase enzyme selectivity, and inhibition by drugs. Drug Metab Dispos.; 41(6): 1273-1284.

10. Elliott HW. (1976) Metabolism of lorazepam. Br J Anaesth.; 48(10): 1017-1023.

11. Ruelius HW. (1978) Comparative metabolism of lorazepam in man and four animal species. J Clin Psychiatry. 39(10 Pt 2): 1115 .

12. Goucher E, Kicman A, Smith N, Jickells S. (2009) The detection and quantification of lorazepam and its 3-Oglucuronide in fingerprint deposits by LC-MS/MS. J Sep Sci. 32(13): 2266-2272. 
13. Scott AK, Cameron GA, Hawksworth GM. (1991) Interaction of metoprolol with lorazepam and bromazepam. Eur J Clin Pharmacol. 40(4): 405-409.

14. Aranko K, Seppälä T, Pellinen J, Mattila MJ. (1985) Interaction of diazepam or lorazepam with alcohol. Psychomotor effects and bioassayed serum levels after single and repeated doses. Eur J Clin Pharmacol. 28(5): 559-565.

15. Jansen M, Mendell J, Currie A, Dow J, He L, Merante D, et al. (2018) Pharmacokinetics, Pharmacodynamics, Safety, and Tolerability of Mirogabalin When Coadministered With Lorazepam, Zolpidem, Tramadol, or Ethanol: Results From Drug-Drug Interaction Studies in Healthy Subjects. Clin Pharmacol Drug Dev. 7(6): 597-612.

16. Chung J-Y, Cho J-Y, Yu K-S, Kim J-R, Lim KS, Sohn D-R, et al. (2008) Pharmacokinetic and pharmacodynamic interaction of lorazepam and valproic acid in relation to UGT2B7 genetic polymorphism in healthy subjects. Clin Pharmacol Ther. 83(4): 595-600.

17. Wettstein JG, Spealman RD. (1988) GABA-related drugs modulate the behavioral effects of lorazepam. Psychopharmacology (Berl). 95(1): 38-42.

Wesnes K, Simpson PM, Jansson B, Grahnén A, Weimann HJ, Küppers H. (1997) Moxonidine and cognitive function: interactions with moclobemide and lorazepam. Eur J Clin Pharmacol. 52(5): 351-358.

18. File SE, Bond AJ, Lister RG. (1982) Interaction between effects of caffeine and lorazepam in performance tests and self-ratings. J Clin Psychopharmacol. 2(2): 102-106.

19. Lister RG, File SE. Performance impairment and increased anxiety resulting from the combination of alcohol and lorazepam. J Clin Psychopharmacol. 1983; 3(2): 66-71.

20. McGowan WA, Dundee JW. The effect of intravenous cimetidine on the absorption of orally administered diazepam and lorazepam. Br J Clin Pharmacol. 1982; 14(2): 207-211.

21. Gonzalez D, Chamberlain JM, Guptill JT, Cohen-Wolkowiez M, Harper B, Zhao J, et al. (2017) Population Pharmacokinetics and Exploratory Pharmacodynamics of Lorazepam in Pediatric Status Epilepticus. Clin Pharmacokinet. 56(8): 941-951.

22. Chamberlain JM, Capparelli EV, Brown KM, Vance CW, Lillis K, Mahajan P., et al. (2012) Pharmacokinetics of intravenous lorazepam in pediatric patients with and without status epilepticus. J Pediatr. 160(4): 667-672.

23. Muchohi SN, Obiero K, Newton CRJC, Ogutu BR, Edwards G, Kokwaro GO. (2008) Pharmacokinetics and clinical efficacy of lorazepam in children with severe malaria and convulsions. $\mathrm{Br}$ J Clin Pharmacol. 65(1): 12-21.

24. Maytal J, Novak GP, King KC. (1991) Lorazepam in the treatment of refractory neonatal seizures. J Child Neurol. 6(4): 319-323.

25. Deshmukh A, Wittert W, Schnitzler E, Mangurten HH. (1986) Lorazepam in the treatment of refractory neonatal seizures. A pilot study. Am J Dis Child. 140(10): 1042-1044.

26. Lee DS, Wong HA, Knoppert DC. (1994) Myoclonus associated with lorazepam therapy in very-low-birth-weight infants. Biol Neonate. 66(6): 311-315.

27. Glauser T, Shinnar S, Gloss D, Alldredge B, Arya R, Bainbridge J, et al. (2016) Evidence-Based Guideline: Treatment of Convulsive Status Epilepticus in Children and
Adults: Report of the Guideline Committee of the American Epilepsy Society. Epilepsy Curr. 16(1): 48-61.

28. Chin RFM, Neville GR, Peckham C, Wade A, Bedford H, Scott RC. (2008) Treatment of community-onset, childhood convulsive status epilepticus: a prospective, population-based study. Lancet Neurol. (8): 696-703.

29. Qureshi A, Wassmer E, Davies P, Berry K, Whitehouse WP. (2002) Comparative audit of intravenous lorazepam and diazepam in the emergency treatment of convulsive status epilepticus in children. Seizure. 11(3): 141-144.

30. Crawford TO, Mitchell WG, Snodgrass SR. (1987) Lorazepam in childhood status epilepticus and serial seizures: effectiveness and tachyphylaxis. Neurology. 37(2): 190-195.

31. Yager JY, Seshia SS. (1988) Sublingual lorazepam in childhood serial seizures. Am J Dis Child.; 142(9): 931-932.

32. Appleton R, Sweeney A, Choonara I, Robson J, Molyneux E. (1995) Lorazepam versus diazepam in the acute treatment of epileptic seizures and status epilepticus. Dev Med Child Neurol.; 37(8): 682-688.

33. Farnaghi F, Rahmani R, Hassanian-Moghaddam H, Zamani N, McDonald R, Gholami N, et al. (2020) Oral clonazepam versus lorazepam in the treatment of methamphetamine-poisoned children: a pilot clinical trial. BMC Pediatr. 20(1): 543. doi: 10.1186 .

34. McTague A, Martland T, Appleton R. (2018) Drug management for acute tonic-clonic convulsions including convulsive status epilepticus in children. Cochrane Database Syst Rev. 1(1): CD001905. doi: 10.1002.

35. Appleton R, Macleod S, Martland T. (2008) Drug management for acute tonic-clonic convulsions including convulsive status epilepticus in children. Cochrane Database Syst Rev. (3): CD001905. doi: 10.1002 .

36. Pinto RF, Turnbull J. Lorazepam v. (2016) diazepam for pediatric status epilepticus. CJEM. 18(3): 235-238.

37. Anderson M, Tambe P, Sammons H, Mulla H, Cole R, Choonara I. (2012) Pharmacokinetics of buccal and intranasal lorazepam in healthy adult volunteers. Eur J Clin Pharmacol. 68(2): 155-159.

38. Papini O, da Cunha SP, da Silva Mathes ADC, Bertucci C, Christine E, Moisés D, et al. (2006) Kinetic disposition of lorazepam with focus on the glucuronidation capacity, transplacental transfer in parturients and racemization in biological samples. J Pharm Biomed Anal. 40(2): 397-403.

39. McBride RJ, Dundee JW, Moore J, Toner W, Howard PJ. (1979) A study of the plasma concentrations of lorazepam in mother and neonate. Br J Anaesth. 51(10): 971-978.

40. Nishimura A, Furugen A, UmazumeT, Kitamura S, Soma M, Noshiro K, et al. (2021) Benzodiazepine Concentrations in the Breast Milk and Plasma of Nursing Mothers: Estimation of Relative Infant Dose. Breastfeed Med. 16(5): 424-431.

41. Lemmer P, Schneider S, Mühe A, Wennig R. (2007) Quantification of lorazepam and lormetazepam in human breast milk using GC-MS in the negative chemical ionization mode. $J$ Anal Toxicol. 31(4): 224-226.

42. Dencker SJ, Johansson G, Milsom I. (1992) Quantification of naturally occurring benzodiazepine-like substances in human breast milk. Psychopharmacology (Berl). 107(1): 69-72.

43. Whitelaw AG, Cummings AJ, McFadyen IR. (1981) Effect of maternal lorazepam on the neonate. $\mathrm{Br}$ Med J (Clin Res Ed). 282(6270): 1106-1108. 